\title{
THE MALE REPRODUCTIVE SYSTEM OF THE REEF SQUID SEPIOTEUTHIS LESSONLANA LESSON, 1830 (MOLLUSCA: CEPHALOPODA) FROM THE GULF OF SUEZ
}

\section{Waheed M. Emam and Reda H. Aly}

Zoology Department, Faculty of Science, Ain Shams University

(Received: December 15, 1999)

Key words: Cephalopods, squid, Sepioteuthis lessoniana, male reproductive system, anatomy, histology, spermatophore, spermatophoric formation

\section{ABSTRACT}

Cepioteuthis lessoniana Lesson, 1830 , represents the most common species of squids in the Red Sea. It was chosen for a detailed study of the macro- and microscopic anatomy of its male reproductive system with special reference to the structure of its spermatophores and the method of their formation.

The male reproductive system is differentiated into a single testis and a gonoduct which consists of a vas deferens, a complex spermatophoric organ, a spermatophoric duct and a spermatophoric sac that ends with a muscular conducting tube. The testis is formed of a large number of closely compact seminiferous tubules containing different stages of spermatogenesis. The spermatophoric organ is composed of six glands: mucilagenous I \& II, ejaculatory appartaus, middle and outer tunic and accessory gland with its appendix. The structure of each of these glands was demonstrated and discussed.

The spermatophore of $S$. lessoniana is a minute structure that consists of a spermatophoric cord and an ejaculatory apparatus connected together through the connective region. The structure of different parts of the spermatophore and the method of their formation were studied and discussed. 


\section{INTRODUCTION}

Sepioteuthis lessoniana Lesson, 1830 , is a nertic species occurring from the surface down to at least $100 \mathrm{~m}$ depth. It is an indopacific species that is found in the Red Sea, Arabian sea, North Australia and North to Central Japan and eastward to the Hawiian islands (Roper, 1984). In spite of its wide distribution and the role it plays in the commercial catch of the reef squids in the indo-pacific fisheries, yet little is known about the structure of its reproductive organs and spermatophoric formation.

Silas (1983) found that males of S. lessoniana in the Indian water reach their first sexual maturity at $10 \mathrm{~cm}$ mantle length. On the other hand, Roper et al. (1984) reported that males of this species attain their sexual maturity at age of 10-14 months and their life span extends to 2.5 years.

The male reproductive system of different species of squids was studied by Drew (1910 \& 1919); Austin et al. (1964); Fields (1965); Badenhorst (1974); Maxwell (1975) and Grieb and Beeman (1978).

The structure of spermatophore of the squid Loligo had been investigated by many authors (Blancquaert, 1925; Austin et al., 1964; Fields, 1965; Arnold \& Williams-Arnold, 1977).

This work aims to study the macro- and microscopic anatomy of the male reproductive system of Sepioteuthis lessoniana from the Gulf of Suez. Moreover, this study will provide the necessary information about the structure of the spermatophore and the method of its formation in this species . This contribute to the basic knowledge about this group of cephalopods in the Red Sea as well as in other parts of the world.

\section{MATERIAL AND METHODS}

Specimens of the reef squid Sepioteuthis lessoniana were collected from the Gulf of Suez. Mature male individuals were selected for studying the morphology and histology of their reproductive organs. 
The male reproductive system of the Reef Squid Sepioteuthis Lessoniana From The Gulf of Suez

Their dorsal mantle length ranged from $25-30 \mathrm{~cm}$ and their average weight was about $250 \mathrm{~g}$.

For anatomical studies fresh and preserved specimens in $10 \%$ formalin were used, while histological examination was conducted with live specimens. The testis was cut into small pieces before fixation, while the whole vas deferens, spermatophoric organ and sac were directly fixed in aquous Bouin for $48 \mathrm{~h}$. Fixed organs were dehydrated, cleared and embedded in wax as usual. Serial sections (6-8 um thickness) were stained with haematoxylin-eosin.

Smear of testis was used to study the morphology of the spermatozoa. Whole fresh spermatophores were removed from the spermatophoric sac and fixed in Bouin's solution then stained with haematoxylin-eosin to study their morphology. The structure of different parts of the spermatophore, its layers and formation were investigated in serial sections taken through spermatophoric organ and sac (in situ). The released sperms under the fluid pressure inside spermatophore was photographed.

\section{RESULTS}

Macro- and microscopic structure :

The male reproductive system of Sepioteuthis lessoniana is differentiated into a single testis and left gonduct. The latter consists of the vas deferens, the complex spermatophoric organ, the spermatophoric duct and the spermatophoric sac (Needham's sac) which continues into the muscular terminal conducting organ (Fig. $1 \mathrm{a} \&$ b).

A- The testis :

This is a median white elongated structure that is suspended in the coelom by a mesentery (Fig. 1a). It increases greatly in size with maturation of the animal and its growth in length and age. It has a dorsal notch in its anterior edge which extends posteriorly as a septum. It is 
enclosed within a testicular capsule (sheath) which is formed of an outer simple squamous layer followed by a connective tissue with blood vessels and muscle fibers.

The testis in mature specimens consists of a large number of seminiferous tubules which appear as polygonal follicles in transverse sections (Fig. 2 a). These follicles are connected together by a very thin layer of connective tissue which is richly supplied with blood vessels. Each follicle has an outer epithelial layer of squamous cells which is known as membrana propria. Different stages of spermatogenesis are found along the entire length of the follicles. These include spermatogonia, spermatocytes, spermatids and spermatozoa (Fig. 2 b). The spermatogonia are rounded and densely stained. The spermatocytes are aggregated in groups of small cells that have rounded and more dense nuclei. Spermatids and sperms are present in the center of each follicle. The spermatids vary in shape and size and have rounded to oval nuclei. Each spem is formed of a small oval head $(12 \times 7 \mathrm{um})$ with terminal acrosome and large oval nucleus; a neck (10 um) and a long tail (35 um) (Fig. 3).

The testis discharges its contents through a pore on its ventral surface to the testacular capsule which then reach the vas deferens.

B- The vas deferens:

This extends from the anterio-dorsal surface of the testis and enters the ventral part of the spermatophoric organ (Fig. 1 a). It starts by a ciliated funnel-shaped structure, the ampulla, which leads to a convoluted canal. The lumen of the ampulla has numerous tree-like folds. Each fold has a lining epithelium of ciliated columnar cells with oval to rounded nuclei (Fig. 4). The convoluted region of the vas deferens has a wide lumen and short folds with lining epithelium similar to that of the ampulla. The lumen 
of the ampulla and the convoluted portion is densely packed with sperm mass (Fig. 5).

\section{C- The spermatophoric organ :}

This lies on the left side of the body, ventral to the vas deferens and testis and embraced by the curvature of the spermatophoric sac (Fig. 1 a). This organ is a complex structure enclosed by the genital sac and formed of six glands; mucilagenous I and II, ejaculatory appartaus, middle and outer tunic and accessory with its appendix (Fig. 1 b).

\section{1- The mucilaginous gland $I$ :}

This lies lateral to the vas deferens, ventral to the spermatophoric sac and dorsal to the mucilaginous gland II and the accessory gland (Fig. 1 $a \& b)$.

The lining epithelium of this gland is formed of outer ciliated columnar cells with basal rounded to oval nuclei and elongated subepithelial cells that open between them into the lumen of the gland and rest on the basement membrane (Figs $6 \& 7$ ). The elongated cells differ in nature of their cytoplasm inclusions according to their position in the gland. Cells located at the ventral side of the lumen of the gland are multi-layered and have reticular cytoplasm (Fig. 6). However, cells lying at the dorsal wall of the lumen have granular cytoplasm (Fig. 7).

\section{2- The mucilaginous gland II :}

This gland lies within the curvature of the combined ejaculatory apparatus and middle tunic gland (Fig. 1 a \& b). It has a U-shape lumen. The epithelial lining of the gland consists of outer ciliated columnar cells and several types of subepithelial elongated ones. In the posterior part of the gland, the subepithelial cells are tall secretory with several granulated vacuoles arranged in many layers (Fig. 8). In the ventral wall of the gland, the subepithelial lining is formed of two types of cells; the first with long, wavy, filament-like strands that extend from short distance away from 
their oval nuclei in the cytoplasm, while the second type has small granular cytoplasmic inclusions (Fig. 9).

A typhlosolar ridge is formed inside the mucilagenous gland II as an invagination of the lining epithelium and connective tissue of its ventral part (Fig. 10). The epithelial lining of the ridge consists of ciliated columnar cells and has a subepthelium of secretory cells. The typhlosolar ridge extends downward to form a conduit which has a similar histological structure to the ridge. The central core of the conduit has a chondroid like structure in the form of homogeneous ground substance or matrix, with lacunae of different sizes and some blood vessels and is crossed by long wavy extensions of fibroblasts (Fig. 11).

3-Ejaculatory apparatus gland:

It has a U-shaped lumen and a typhlosol with central thick connective tissue. Its epithelial lining is made up of short columnar cells and nulti-layered subepithelial cells with numerous granulated vacuoles similar to those in the posterior part of mucilaginous gland II (Fig. 8).

\section{4- The middle tunic gland:}

It is C-shaped structure with an external ventral groove formed from the invagination of connective tissue towards the lumen of the gland (Fig. 1 a \& b). The middle tunic gland has an internal typhlosolar ridge with chondroid connective tissue. The ventral wall of this gland has an outer layer of ciliated columnar cells and inner subepithelial elongated ones with reticular cytoplasm (Fig. 12). The dorsal wall of this gland has outer ciliated columnar epithelium and inner multi-layered subepithelium of tall glandular cells (Fig. 13).

\section{5- The outer tunic gland:}

This is a long narrow glandular ciliated tube-like form connecting the middle gland with the accessory gland (Fig. 1b). Histologically, its epithelial lining cells are ciliated columnar, while its subepithelium is multi-layered and 
The male reproductive system of the Reef Squid Sepioteuthis Lessoniana From The Gulf of Suez

has glandular secretory cells, arranged in different levels with basal rounded to oval nuclei (Fig. 14).

6- The accessory gland:

It is a sac like structure that lies on the dorsal surface of the outer tunic gland. Its inner surface is provided with longitudinal folds. Each fold is covered with an outer flattened cells with oval nuclei and has an inner subepithelium formed of wedge shaped cells that open between the outer ones into the lumen of the gland (Fig. 15).

\section{7- Appendix of the accessory gland:}

This lies dorsal to the accessory gland and connected to the spermatophoric sac through the spermatophoric duct (Fig. 1 b). It has a Ushaped lumen due to the presence of an inner incomplete fold that divides it into an afferent and an efferent limbs (Fig. 16). Histologically, the epithelium of the two limbs as well as that of the wall of the gland is made up of outer ciliated columnar cells and glandular secretory subepithelial ones that open between them.

A blind curved glandular gland extends from the posterior part of the afferent limb and lies lateral to the accessory gland (Fig. $1 \mathrm{~b}$ ).

D- The spermatophoric duct:

It originates from the efferent limb of the appendix of the accessory gland. It runs posteriorly and dorso- laterally to the vas deferens, to open anteriorly into fundus of the spermatophoric sac. This duct is divided into a proximal portion with many folds of ciliated columnar cells (Fig. 17) and a distal part that has a wide lumen with short ciliated folds (Fig. 18). The distal portion of the spermatophoric duct has no folds and cilia and open into the fundus of spermatophoric sac (Fig. 1 b). 


\section{E- The ciliated canal:}

It opens into the posterior part of the outer tunic gland close to its junction with the anterior end of the middle tunic gland (Fig. Ib). This canal has an inner lining epithelium formed of ciliated columnar cells. In fully formed specimens the lumen of this canal is full with milky secretion.

\section{D- The spermatophoric sac:}

This is a spindle-shaped storage sac for the fully formed spermatophores which has a blind posterior end called fundus and an anterior conducting terminal organ with a thick wall, that opens in the mantle cavity. The spermatophoric sac of the fully mature specimen is occupied with compact mass of spermatophores that are arranged in two parallel rows (Figs 1a , 19). The lining epithelium of the terminal organ consists of low columnar cells followed by a thick layer of circular and longitudinal muscle fibres and connective tissue (Fig. 20). Their number varies from 80 to 90 in mature specimens with $20-25 \mathrm{~cm}$ mantle length. The ejaculatory apparatus of the spermatophore is directed downward inside the fundus of the spermatophoric sac. Spermatophores are spirally arranged in a tree-like form lamellae which arise from the thin-walled fundus.

\section{The spermatophore :}

The mature spermatophore is a transparent tubular structure with slightly curved anterior end. It measures about $16 \mathrm{~mm}$ in length and $2 \mathrm{~mm}$ in width. It is mainly formed of two portions; the spermatophoric cord or reservoir and the ejaculatory apparatus connected together by the connective (Figs $21 \& 22$ ).

The spermatophoric cord is a uniform tube occupied by dense sperm mass. Its length is nearly twice that of the ejaculatory apparatus. The latter is divided into a basal sac and a terminal horn, separated from 
each other by a thin groove. The horn is coiled anteriorly and forms a compact twist that is compressed to form a cap from which a very thin thread extends (Fig. 21).

Three inner successive layers 1,2 and 3 enclosed the spermatophoric cord and are followed by other three outer layers $4,5 \& 6$ that extend to surround the whole spermatophore (Figs $23 \& 24$ ). Layers 1 and 2 are very thin and hardly observed, while layer 3 is thick. The connective is coated by layers 3, 4, 5 and 6 (Fig. 22). The sac and horn are ensheathed by layer 3 which is differentiated according to its staining affinity into 7 sublayers (a, b, c, d, e, f \& g) (Figs $25 \& 26$ ). The sublayer $3 \mathrm{~b}$ was not stained with haematoxylin-eosin and may represent a space between sublayers $\mathrm{a}$ and $\mathrm{c}$. On the other hand, sublayer $3 \mathrm{~g}$ is fluid filled.

The sperms inside the spermatophoric cord are embdded in a fluid under a high pressure. When a fresh spermatophore of $S$. lessoniana was cut at the base of its ejaculatory apparatus, sperms strongly eject outside the cord (Fig. 28).

\section{Spermatophoric formation:}

The testis empties mature sperms into the coelomic capsule surrounding it where they are immediately picked up by cilia of the ampulla (Fig. 4) of the vas deferens and then aggregate into a loose continuous sperm mass (Fig. 5). During the passage of this mass into the narrow lumen of mucilagenous gland I, the sperm mass is mixed with its viscous glandular secretion and changes into a slender sperm rope which becomes tightly spiralled and coiled with this secretion. Inside mucilagenous gland II, the spermatophoric cord is formed and the sperm rope becomes arranged in circles prependicular to the whole length of this cord. Meanwhile, layers 1,2 and 3 and the connective are formed. The sac and the spiral horn are observed within thei spermatophores inside the lumens of mucilagenous gland II and cjaculatory apparatus gland. 
Secretions of the middle and outer tunic glands add more spermatophoric membranes. The horn of the spermatophore coils forming the twist which is compressed by the cap in the lumen of the accessory gland and its appendix.

Sections through a completely formed spermatophores were observed in the spermatophoric duct (Fig. 17), where it passes into the spermatophoric sac at an angle, so that the posterior end of the spermatophoric cord becomes directed towards the coducting terminal organ.

\section{DISCUSSION}

The male reproductive system of the reef squid Sepioteuthis lessoniana has received a little attention. Most of the previous studies were focused on different species of Loligo. Its general morphology corresponds to that described in other species of Loliginidae (Drew, 1911; Badenhorst, 1974) and Sepiidae (Blancquaert, 1925; Tompestt, 1939; Bawab \& Ismail, 1981; Emam, 1984).

In mature testis of $S$. lessoniana, spermatogenesis takes place within its seminiferous tubules which includes four stages namely; spermatogonia, spermatocytes, spermatids and spermatozoa. Similar stages were recorded in other groups of cephalopods (Badenhorst, 1974; Enam, 1984; Arnold \&Williams-Amold, 1978; Sauer \& Lipiniski, 1990; Gaber et al., 1998).

The general structure and histology of the vas deferens in $S$. leessoniana are comparable the description given by Badenhorst, (1974) on Loligo reynaudii and Emam (1984) on Sepia savigyni.

The microscopic details of different glands forming the spermatophoric organ show slight variations in various species of Loliginidae. The secretory cells of mucilaginous gland $I I$ and the 
The male reproductive system of the Reef Squid Sepioteuthis Lessoniana:

ejaculatory apparatus of $S$. lessoniana were found to contain spherical granules instead of the stellar objects observed by Badenhorst (1974).

The tree-like folds found in the spermatophoric sac of $S$. lessoniana are similar to that described by Drew (1919) on Loligo pealei and Badenhorst (1974) on Loligo reynaudii and El-Bawab (1986) on Sepia officinalis. Blancquaert (1925) mentioned that the ciliated canal in Sepia officinalis represented an evacuation path for sperms not incorporated into the spermatophore formation and the residual secretion to the outside through the genital sac. This cann't be confirmed in the present study, however milky secretion without sperms was only observed.

The term terminal organ used in the present study after Mann et al.(1970) was found more acceptable than using the term penis (Drew, 1910; Austin et al., 1964) since the latter organ is an intromittent or copulatory organ, while in male cephalopods, the hectocotylus arm is an alternative.

The spermatophore is formed by different groups of invertebrates like platyhelminthes (Hyman, 1951; Alexander, 1979); crustaceans (Mathews, 1957, Bawab, 1970; Sherief, 1975), gastropods (Sasaki, 1929). As well as by some protochordates and some vertebrates (Hadfield, 1975 and Francis, 1934 respectively).

The basic structure of the spermatophore of $S$. lessoniana is a tubular strcuture with a slightly anterior end similar to that in most species of cephalopods, however its parts were given different names by various authors. On the other hand, some species have curved spermatophores and a few species with exceptionally large spermatophores that hold them in a bent or even coiled condition, because of the restrictive size of the spermatophoric sac (Arnold \& William Amold, 1977). 
The number and length of spermatophores in cephalopods vary from one group to another. It was less than 100 spermatophores in the spermatophoric sac of fully mature male of $S$. lessoniana, which is similar to that given by Austin et al. (1964) for Loligo pealii. However, the number of spermatophores was up to few hundreds in some squids (Drew, 1919), in Sepia officinalis (Arnold \& Williams-Amold, 1977), in S. pharaonsis and S. dollfusi (Gaber et al., 1998)

In the present study the average length of the spermatophore of $S$. lessonina was about $16 \mathrm{~mm}$. Smaller spermatophore lengths were recorded for other species of squids; $3 \mathrm{~mm}$ for Loligo marmoae (Marchand, 1913), $8 \mathrm{~mm}$ for $L$ opaliscens (Fields, 1965), $10 \mathrm{~mm}$ for $L$. pealii (Austin et. al., 1964). On the other hand, the maximum length of the spermatopore of L. forbesi was about $25 \mathrm{~mm}$ (Boyle et. al., 1995). Moreover a great variation in the length of the spermatophore was found within different genera of cephalopods. It ranges from $0.5 \mathrm{~mm}$ in Sepia officinalis (Tompsett, 1939) to one meter in Octopus dolfeini martini. (Mann et al., 1966). Fields (1965) reported the presence of direct relationship between the length of the spermatophore and that of the mantle of the adult male specimens of the squid Loligo opalescens.

The differences in size and shape of different parts of spermatophore can be used as a taxonomical tool to differentiate between cephalopod species (Marchand, 1913; Adam, 1960).

The spermatophore of $S$. lessoniana is formed of spermatophoric cord and ejaculatory apparatus connected together through a connective. This agrees with the description given for Sepia officinalis by Blancquaert (1925) and Bawab \& Ismail (1984a) and for S. savignyi by Emam (1984). However, Arnold and Williams-Amold (1977) didn't mention the presence of such region in the spermatophore of Loligo pealei. 


\section{The male reproductive system of the Reef Squid Sepioteuthis Lessoniana'}

The spermatophoric cord of $S$. lessoniana consists of a sperm rope embedded in a spermatophoric substance and all are ensheathed externally with three coats $(1,2$ and 3$)$ to be protected. The term spermatophoric cord used in the present study is satisfactory to describe the components of this structure. However, the terms sperm mass or sperm rope given by Austin et al. (1964) and Wells \& Wells (1977) respectively didn't express the meaning of its components.

Ejaculatory apparatus of spermatophore in cephalopods has an important role in dehiscence of spermatophore (Austin et al., 1964 \& Ismail, 1981). The two parts of ejaculatory apparatus, sac and horn found in $S$. lessoniana are similar to those given by Tompsett (1939) and Ismail (1981) for Sepia officinalis. Meanwhile, the sac corresponds to the cenent body described by Drew (1919), Fort (1937) and Mann et al. (1970). While, the horn coils on itself more than one coil forming a bulged end part, the twist, which is compressed by the cap. This twist is similar to that described by Bawab \& Ismail (1984a) and Emam (1984).

The horn of spermatophore of $S$. lessoniana is surrounded by only one layer (layer 3 ) which is subdivided into 7 components. Similarly, one layer was observed by Bawab and Ismail (1984a) for the spermatophore of Sepia officinalis, however this layer is subdivided into 5 components. Tompsett (1939) and Austin et al. (1964) mentioned that the horm has three membranes in S. officinalis and Loligo pealii respectively.

The histological study of the spermatophore of the present species provided evidence that it is enclosed within three outer layers $(4,5 \& 6)$ which are differentiated from each other by their thickness and staining affinity. These layers correspond to the outer tunic described in $S$. officinalis by Blancquaert (1925) and Bawab and Ismail (1984a), in $S$. savignyi by Emam (1984) and to the fluid space, middle tunic and outer tunic of Loligo pealii respectively (Austin et al., 1964). On the other hand, the inner tunic described in the cuttlefish by Ismail (1981) and 
Emam (1984) corresponds to layer 3 in the present work. The nature of these layers in some cephalopods were biochemically studied by Mann $e t$ al. (1970), Hanson et al. (1973), Brooks et al, (1981) and Mann (1984), and histochemically by Austin et al. (1964) and El-Bawab (1986). Their results revealed that the major organic substances are carbohydrates, proteins and lipid shared as polymerized and/or conjugated forms and the outer layers were formed mainly of mucopolysaccharids, while the inner ones are mucoprotein.

The method of spermatophoric formation in cephalopods has received little interest. Blancquaert (1925), Arnold and Williams-Arnold (1977) and Bawab and Ismail (1984) explained briefly this mechanism on Sepia officialis, while Mann et al. (1970) on Octopus dolfini martini.

In the present study, the spermatophores were found to be arranged in the spermatophoric sac in two parallel rows with their spermatophoric cord directed toward the conducting terminal organ. This is similar to that described by Badenhorst (1974) on Loligo reynaudii, Emam (1984) on S. savignyi and El-Bawab (1986) on Sepia officinalis. The arrangement of spermatophores in this manner seems to be similar in most decapod species and may help in transferring them without releasing of sperms to the seminal receptacle of female through the male hectocotylus arm. Meanwhile, the well developed musculature of the conducting terminal organ of $S$. lessoniana may assisst in passage of spermatophore outside the male reproductive opening. Austin et al. (1964) found that the breakdown of spermatophore cap leads to withdrawal of spermatophoric cord outside the outer cover of spermatophore and releasing of sperms under the pressure of fluid inside spermatophore. The effect of pressure of spermatophoric cord fluid was found to play a great role in releasing of sperms of $S$. lessoniana. 
The male reproductive system of the Reef Squid Sepioteuthis Lessoniana

\section{REFERENCES}

Adam, W. (1960). Cephalopoda from the Gulf of Aquaba, The Sea Fisheries Research Station. Bull., 26(16), Israel, 1-26.

Alexander,R.M. (1979). "The Invertebrates" Cambridge University Press.

Arnold, J .M. and Williams- Arnold , L. D.(1977). Cephalopoda, Decapoda. Reproduction of Marine Invertebrates (Giese A.C \&. Pearse Ed.s ). Acad. Press,New youk . 243-290.

Arnold, J .M. and Williams - Arnold, L. D.(1978). Spermatogenesis of Nautilus pompilius. J. Exp. Zool., 205 (1) : 13-25.

Austin ,C. R, Lutwak-Mann, C.and Mamn , C and Mann,T. (1964).

Spermatophores and spermatozoa of the squid Loligo Pealei. Proc Roy. Soc . Lond., B, 161: 143-152.

Badenhorst, J.H. (1974) : The morphology and histology of the male genital system of the squid Loligo reynaudii d, Orbigny. Annale Univ. Van Stellenbosch,49 (A), 1-36.

Bawab, F. M. and Ismail, S.Z .(1981). The structure of the male reproductive system of Sepia officinalis . Bull . Fac .Sci Alex . Univ., 21 : (4), 119134.

Bawab, F. M. and Ismail , S. Z. (1984a) . Structure of the spermatophore of Sepia officinalis. Bull . Fac. Sci. Alex. Univ. 24: (4), 274-310. Bawab, F. M. and Ismail , S.Z (1984b). The formation of the spermatophore of Sepia officinalis. 1 Role of the testis . Bull. Fac. Sci., Alex Univ., 24 (4): 311-325.

Blancquaert, T. (1925). L' origine et la formation des spermatophores chez les cephalopods decapodes. Cellule Rec .Cytol. Histol., 36 , $315-356$.

Boyle, P.R.; Peirce, , G.J. and Hastie (1995) , Flexible reproductive strategies in the squid Loligo forbesi . Mar. Biol., 121:501-508. 
Drew , G.A. (1910). Sexual activities of the squid Loligo pealei. The spermatophore, its structure ejaculation and formation. J. Morphol., 22 : 327-360.

Drew,G.A. (1919). Sexual activities of the squid Loligo pealei Les. J. Morphol., 32: 3379-435.

El-Bawab, (1986). The spermatophoric organ of Sepia officinalis. Ph.D. thesis, Alexandria, Univ.

Emam, W. M. (1984). Biological studies on some cephalopods common in Egyptian waters. M.Sc. thesis, Ain Shams Univ.

Fields, G. (1965). The structure , development, food relation, reproduction and life history of the squid Loligo opalescens Berry . Calif Fish . Bull., $131: 1-108$.

Fort , G. (1937) : Les spermatophore des cephalopodes. Etude du spermatophore d, Eledone cirrhosa (Lamarck, 1799). Bull. Biol Fr . Belg., $75: 357-373$.

Francis, E.T.B. (1934). "The anatomy of the salamander". Oxford University Press, London.

Gaber, H. R.; Hanlon, R. T.; Hanafy, M. H. and El-Etreby, S. G. (1998). Maturation, fecundity and seasonality of reproduction of two commercially valuable cuttlefish, Sepia pharaonsis and Sepia dollfusi, in the Suez Gulf. Fisheries Research, 36:99-115.

Hadfield, M.G. (1975). Hemichordata. In " Reproduction in Marine Invertebrates"Vol. II; (Giese, A.C.\& Pearse, J.S., eds.), Academic Press, New York, 185-240.

Hyman, L.H. (1951). " The Invertebrates: Platyhelminthes and Rhynchocoela; The Acoelomate Bilateria". Vol. II, McGraw-Hill, New York. 
The male reproductive system of the Reef Squid Sepioteuthis Lessoniana

From The Gulf of Suez

281

Ismail, S. Z. (1981). The structure of the spermatophore and the male reproductive system of Sepia officunalis. M. Sc. Thesis, Faculty of Science, Alexandria University.

Mann, T. (1984): "Spertmatophores", Development, Structure, Biochemical Attributes and Role in the Transfer of Spermatozoa" Springer-Verlag. Berlin.

Mann, T; Martin, A.W. and thiersch, J.B. (1966) : spermatophores and spermatophoric reaction in the giant octopus of the North Pacific, Octopus dofleini martini. Nature, 211:1279-1282.

Mann, T. Martin, W. and Thisrsch , B , J ( 1970 ) : Male reproductive tract, spermatophores and spermatophoric reaction in the giant octopus of the North Pacific. Octopus dofleini Martini. Proc. Roy. Soc. Lond., $175:$ 31-61.

Mann, T.; Karagiannidis, A. and Martin, A.W.(1973): Glycosidases in the spermatophores of the giant octopus, Octopus dofleini martini. Comp. Biochem. Phsiol., 44 (A) : 1377-1386.

Marchand , W . (1913) : Studien uber cephalopoden . II) Uber spermatophoren. Zool N . Y., 26: 169-200.

Matthews, D.C. (1957). Further evidences of Anomura non-pepdunculate spermatophores. Pacific Sci., 2 (4) : 380-385.

Maxwell, W.L. (1975). Spermatogenesis of Eusepia officunlais (L), Loligo forbesi (Steenstrup) and Alloteuthis subulata (L) (Cephalopoda, Decapoda). Proc. R. Soc. Lond. B, 191 : 527-535. Roper, F.E.; Sweeney, M.J and Nauen, C.E. (1984). FAO species catalogue. Vol. 3, cephalopods of the world. An annotated and illustrated catalogue of species of interst to fisheries. FAO Fish. Synop., 3(125) : 1-277. 
Sasaki, M. (1929). A monograph of the Dibranchiata cephlopods of the japanese and adjacent waters. J .Fac. Sci . Univ. Tokyo zool . Suppl. 20, 1-357.

Sauer,W.H. and Lipinski, M.R. (1990). Histological validation of morphological stages of sexual maturity in chokker squid loligo vulgaris reynaudii (Cephalopoda: Loliginidae). S. Apr. J. Mar. Sci., 9:189-200.

Sherief, S.S. (1975). The structure and histology of the male reproductive system of Portunus pelagicus and the formation of the spermatophores. M.Sc. Thesis, Faculty of Science, Alexandria Univ.

Silas, E.G. (1983). The exploited squids and cuttlefish resources of India: A review. Tech. Ext. Ser. Mar. Fish. Inf. Serv., Cochin, (34) : 116.

Tompsett , D . H . (1939). Sepia Liverpool Mar . Biol . Com . memoirs, 32, Univ. Press of Liverpool.

Wells, M. J. and Wells, J. (1977). "Cephalopoda: Octopoda". In "Reproduction of Marine Invertebrates " (Giese A.C.\& Pearse, J. S., Eds). Academic Press, New York. 291-336. 
The male reproductive system of the Reef Squid Sepioteuthis Lessoniana.

From The Gulf of Suez

List of abbreviations

\begin{tabular}{|c|c|c|c|}
\hline ac gl. & : accessory gland & $\mathbf{s}$ & : sperm \\
\hline af 1 & : afferent limb & $\mathrm{s}$ m & : sperm mass \\
\hline $\mathrm{ah}$ & : anterior horn & sa & : sac \\
\hline am & : ampulla & sc c & : secretory cell \\
\hline ap gl & : apendicular gland & sd & : spermatid \\
\hline apx ac gl & : appendix of accessory gland & sg & : spermatogonia \\
\hline bv & : blood vessel & $\mathrm{sp}$ & : spermatophore \\
\hline ce ca & : coelomic capsule & $\mathrm{sp} \mathrm{cr}$ & : spermatophoric \\
\hline cn & : connective & & cord \\
\hline cnt & : connective tissue & $\mathrm{spd}$ & : spermatophoric \\
\hline cvd & : convoluted vas deferens & & duct \\
\hline $\mathrm{cd} t$ & : conducting tube & $\mathrm{sp} \mathrm{sa}$ & : spermatophoric \\
\hline cr & : cord & & $\mathrm{sac}$ \\
\hline ci cl & : ciliated columna & sr C & : supporting cell \\
\hline$d v d$ & : distal vas deferens & st & : spermatocyte \\
\hline e ap & : ejaculatory apparatus & $\mathrm{t}$ & : tail \\
\hline ef 1 & : efferent limb & ts & : testis \\
\hline fc & : flattened cell & ts ca & : testicular capsule \\
\hline fu & : fundus & $\mathbf{v}$ & : vesicle \\
\hline $\mathrm{gc}$ & : granular cell & $v d$ & : vas deferens \\
\hline $\mathrm{gcy}$ & : granular cytoplasm & & \\
\hline g v & : granulated vacuole & & \\
\hline gl d & : glandular duct & & \\
\hline gl sc & : glandular secretory & & \\
\hline $\mathrm{h}$ & : horn & & \\
\hline & : head & & \\
\hline
\end{tabular}




$\begin{array}{ll}\text { md h } & \text { : middle horn } \\ \text { md t gl } & \text { : middle tunic gland } \\ \text { mu gl I } & \text { : mucilagenous gland I } \\ \text { mu gl II } & \text { : mucilagenous gland II } \\ \mathrm{nk} & \text { : neck } \\ \mathrm{p} \mathrm{vd} & \text { : proximal vas deferens } \\ \text { r cy } & \text { : reticular cytoplasm }\end{array}$

\section{Legend of Figures}

Fig. 1a . Camera lucida drawing of unravelled male reproductive system from ventral side. X 1.5

Fig. 1b. Camera lucida drawing of ravelled spermatophoric organ and sac from ventral side. X 1.5

Figures 2-2v: Photomicrograph through different structures of the male reproductive system. Stained with Haematoxylin-eosin

Fig. 2a. T.S. of testis showing the polygonal follicles of seminiferous tubules. X 125

Fig. 2b. T.S. of testis showing different stages of spermatogenesis and blood vessels between follicles of seminiferous tubules. X 3,00

Fig. 3. Unstained freshly prepared spermatozoa. X 400

Fig. 4. T.S of ampulla and the proximal portion of the vas deferens showing their structure. X 125

Fig. 5. T.S. of convoluted portion of the vas deferens filled with sperm mass. $X 30$

Fig. 6.T.S. of the ventral wall of the lumen of mucilagenous gland I indicating outer ciliated cells and inner multi-layered subepithelial cells with reticular cytoplasm. X 250 
The male reproductive system of the Reef Squid Sepioteuthis (essoniana'

Fig. 7.T.S. of the dorsal wall of the lumen of mucilagenous gland I showing cells of its subepithelial multi-layered with granular cytoplasm. X 300

Fig. 8. T.S. of the dorsal part of mucilaginous gland II to show granulated vacuoles in cytoplasm of its subepithelial layer. X 500

Fig. 9. T.S. of the ventral part of mucilagenous gland II to indicate the presence of two types of cells in its subepithelial layer ; one with long-wavy filaments and the other with granular cytoplasm. X 300

Fig. 10. T.S. of typhlosolar ridge of mucilagenous gland II showing its lining epithelium. X 125

Fig. 11. T.S. of conduit of mucilagenous gland II to show its chondroid like structure. X 250

Fig. 12. T.S. of the ventral wall of the middle tunic gland showing the multilayered subepithelium with its reticular cytoplasm. X 300

Fig. 13. T.S. of the dorsal wall of the middle tunic gland indicating the presence of tall glandular cells in its subepithelium. X 400

Fig. 14. T.S. of the outer tunic gland showing the glandular secretory cells of its subepithelium. X 250

Fig. 15. T.S. of the accessory gland to show the outer flattened epithelial cells and the inner wedge shaped ones. X 600

Fig. 16. T.S. of the appendix of the accessory glands with its afferent and efferent limbs containing sections of spermatophoric cord. X 125

Fig. 17. T.S. of the proximal portion of the spermatophoric duct showing its ciliated columnar epithelium and sections of ejaculatory parts of two spermatophores in its lumen. X 300

Fig. 18. T.S. of the distal portion of spermatophoric duct showing its short folds and wide lumen. X 50 
Fig. 19. Oblique T.S. of the proximal portion of conducting tube showing sections of spermatophoric cord for a number of spermatophores arrangement parallel to each other. X 30

Fig. 20. Oblique T.S. of the distal portion of spermatophoric sac containing sections through spermatophoric cord. X 30

Figures 21-27 : Photomicrographs of spermatophore and its different components stained with Haematoxylin-eosin.

Figs $21 \& 22$. Part of the fully formed spermatophore showing its spermatophoric cord, connective, ejaculatory apparatus (sac \& horn) and the different surrounding layers. X $50 \& 250$ respectively.

Fig. 23. L.S. through the spermatophoric cord showing sperm mass and the surrounding layers. $X 300$

Fig. 24. T.S. through the spermatophoric cord showing spirally arranged sperm mass with its different layers. X 125

Fig. 25. T.S. through the sac of the ejaculatory apparatus. $X 800$

Fig. 26. T.S. through the middle region of the horn showing the differentiation of layer 3 into 7 sublayers. X 600

Fig. 27. living sperms released from the fresh spermatophore cut at the base of its ejaculatory apparatus. Unstained, X 125 

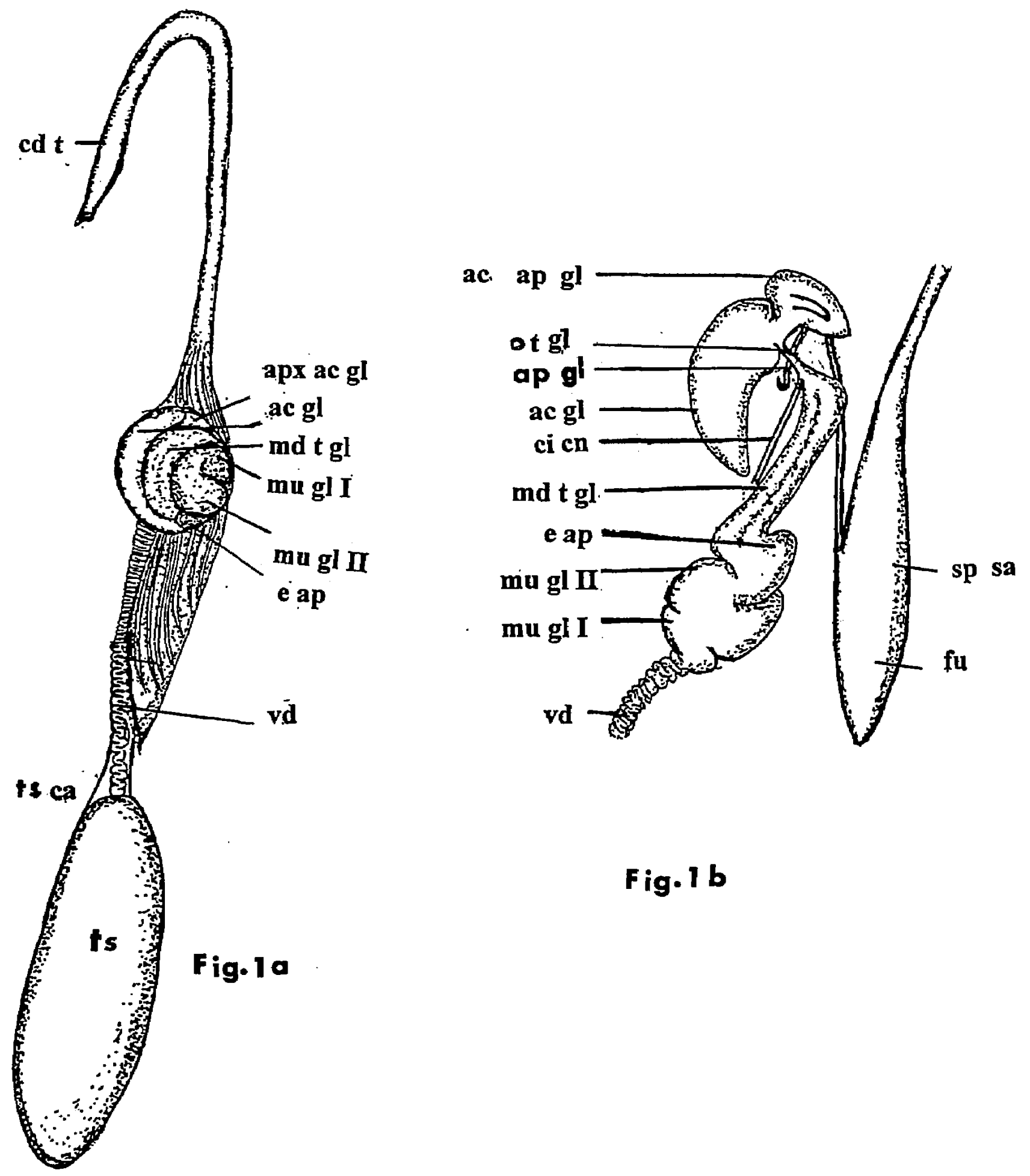

Fig. 1 b 

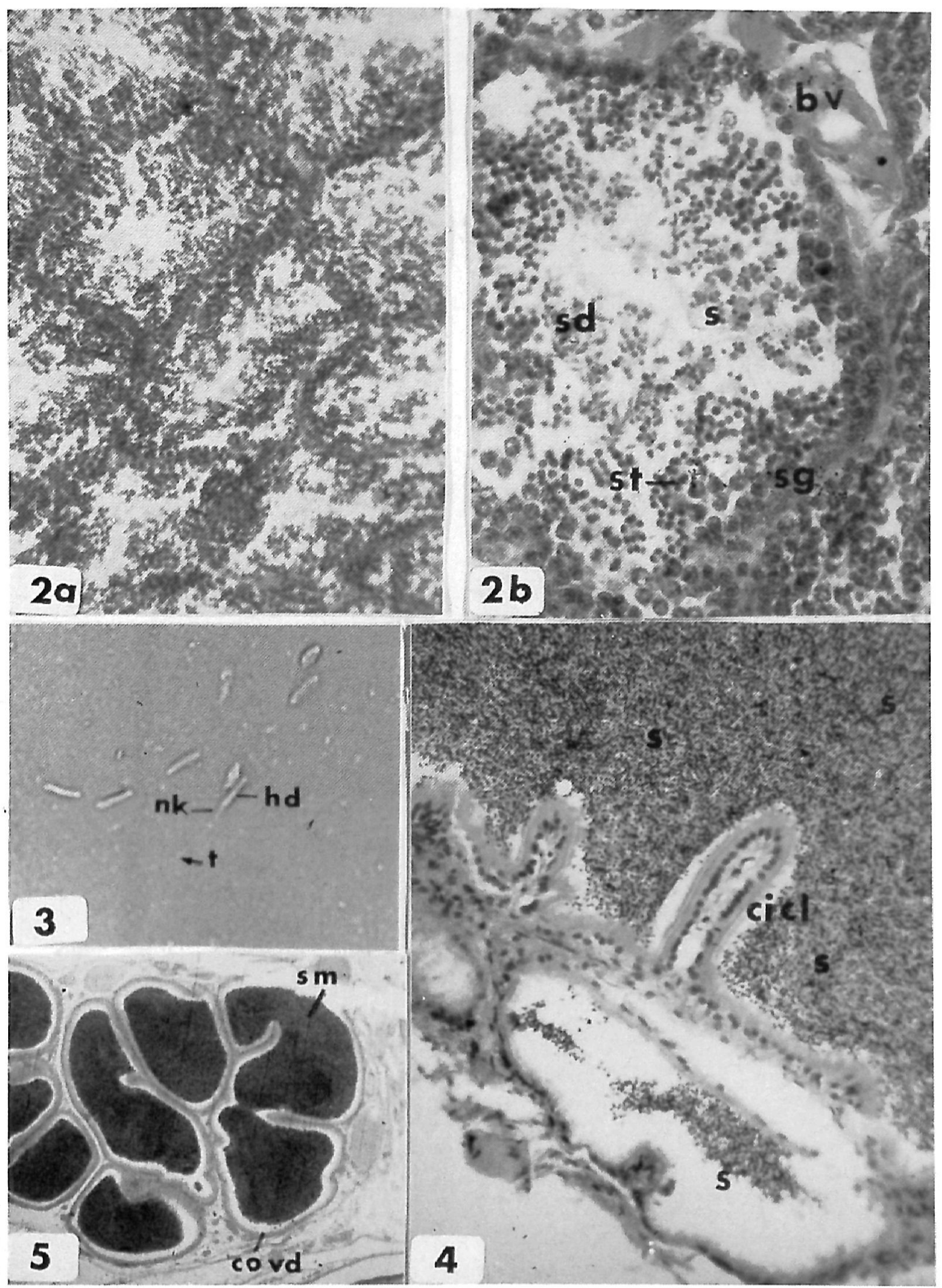







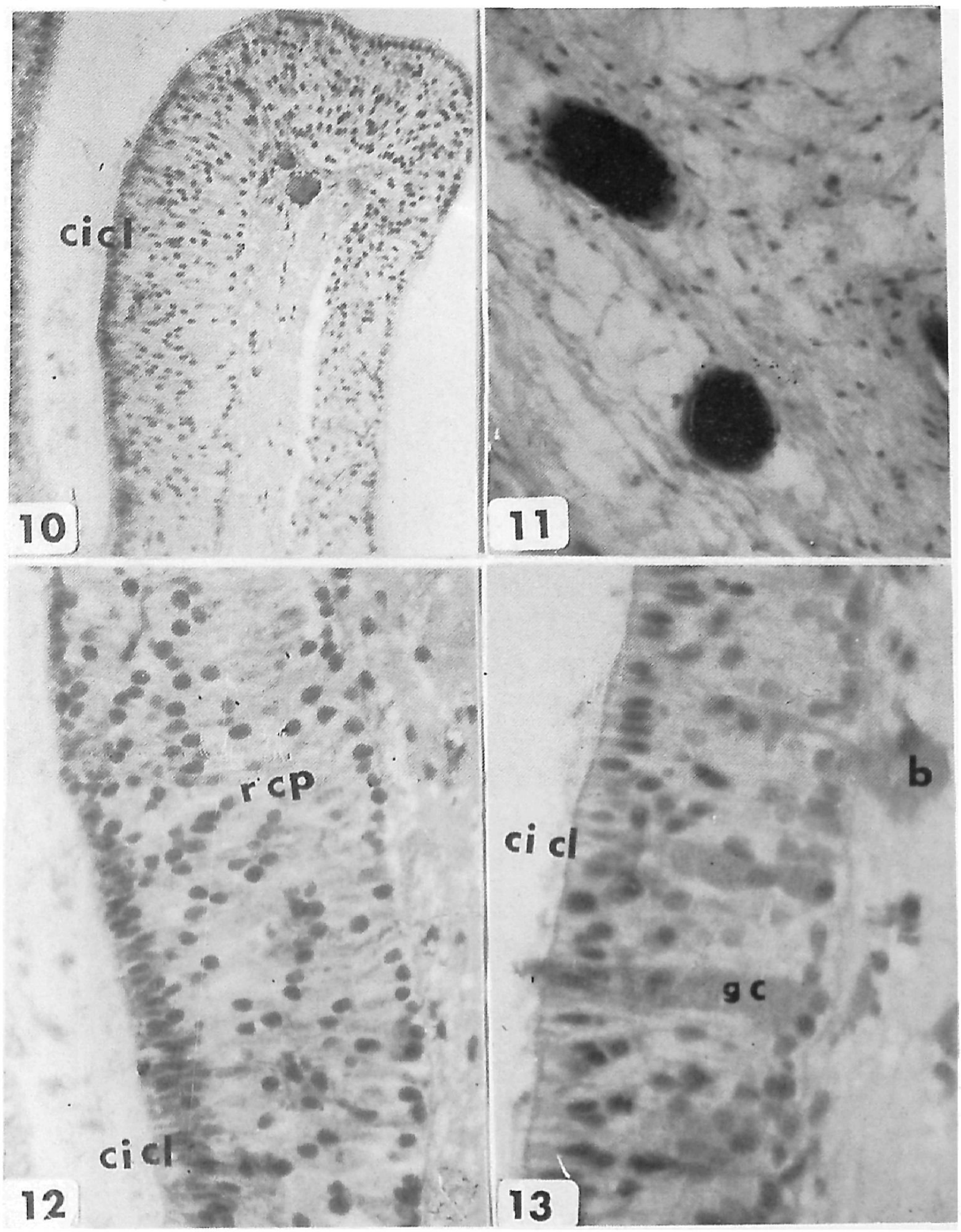




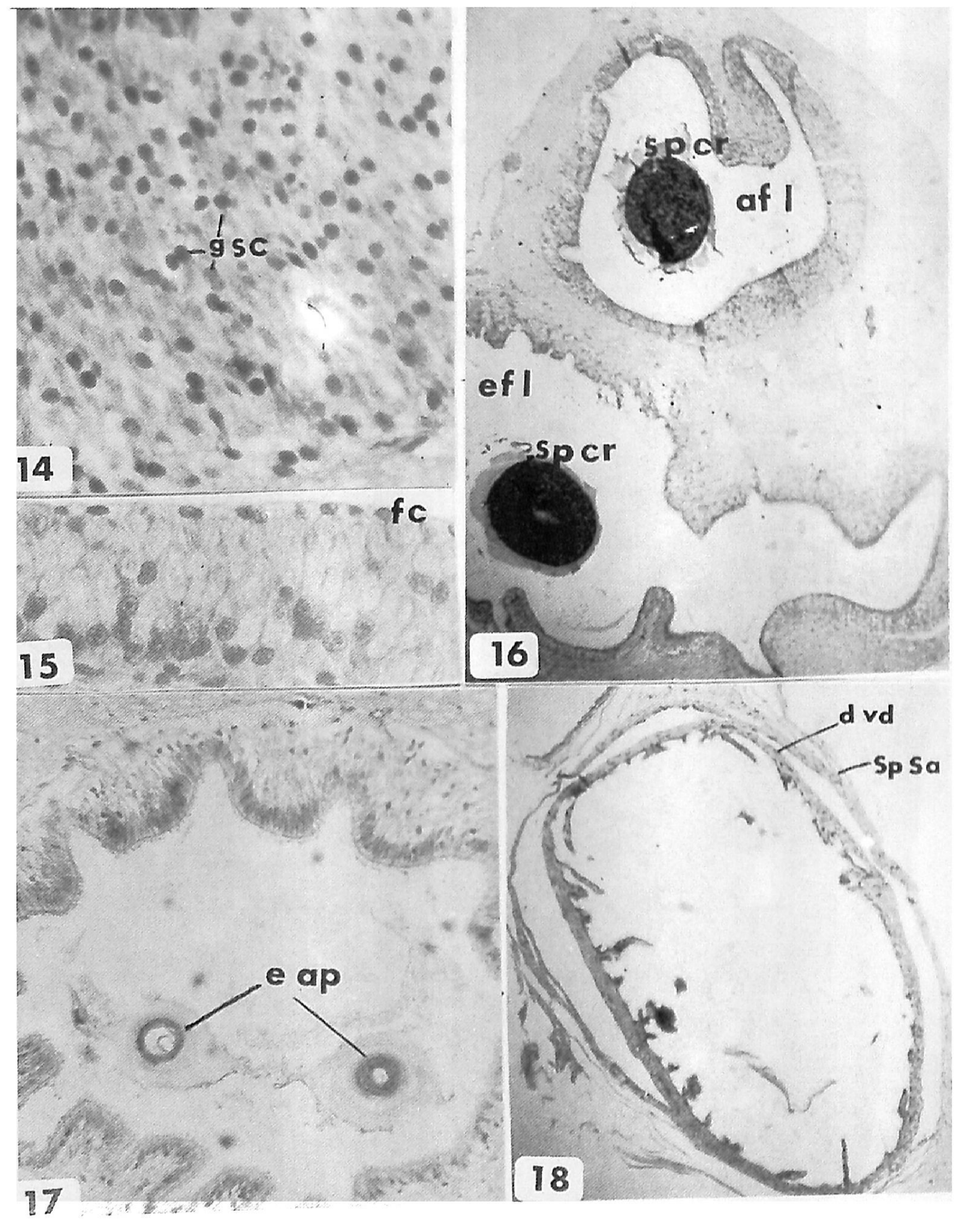




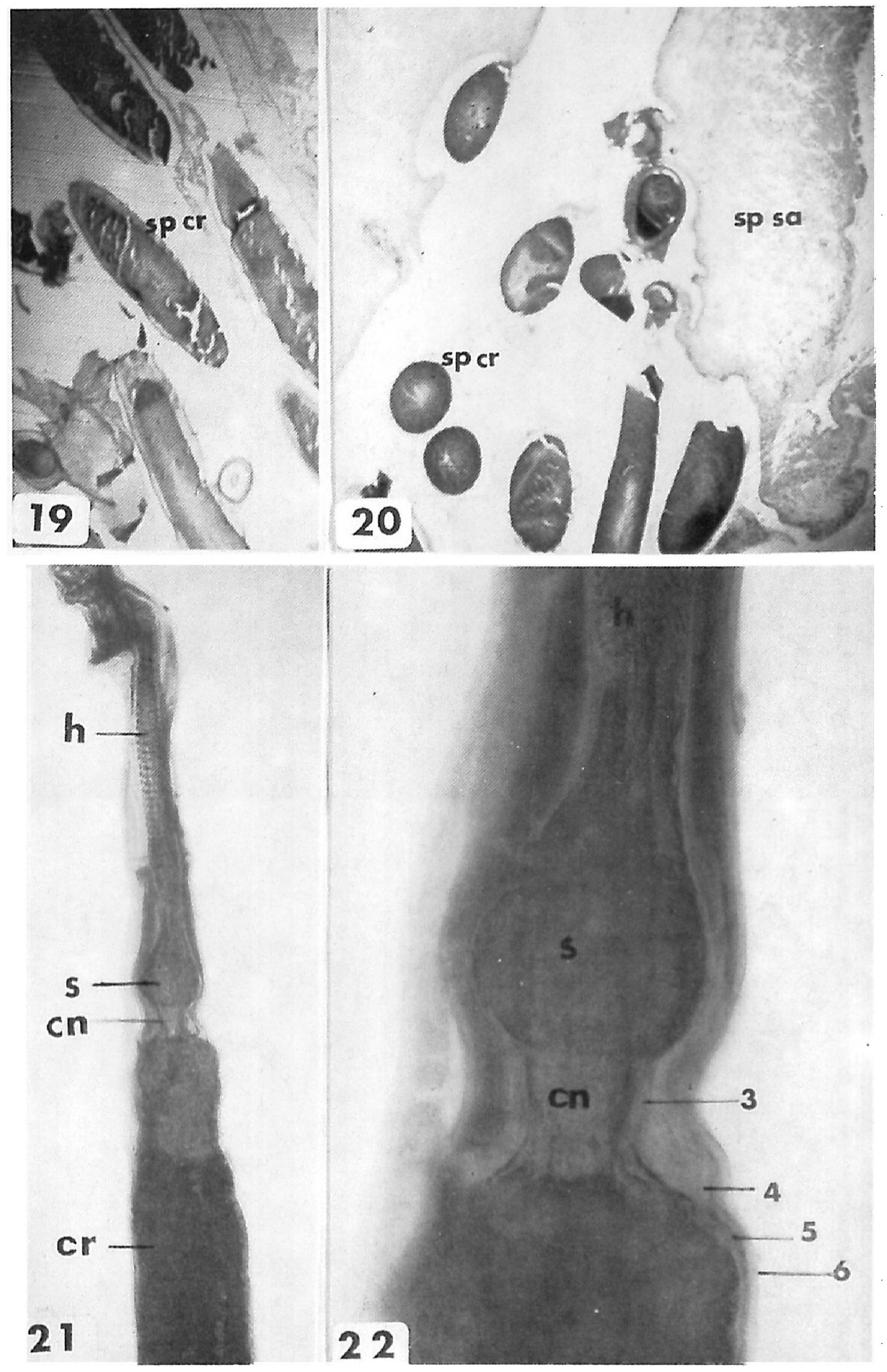



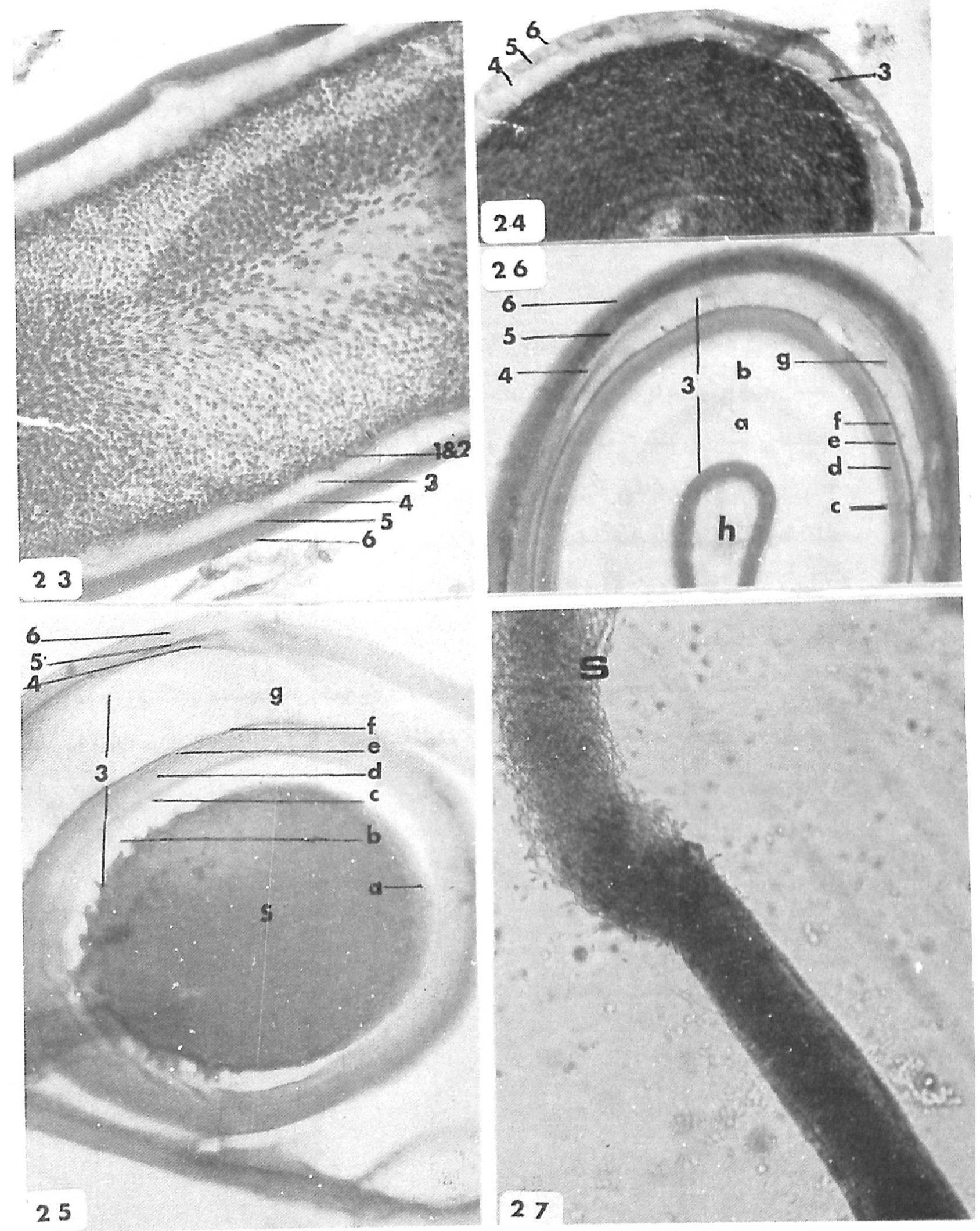